\title{
PRESENTACIÓN DEL VOLUMEN
}

Es un placer presentar al lector el vigésimo sexto volumen de nuestros Estudios Hispánicos, que aparece treinta años después de la publicación de su primer número. Este veía la luz en 1988 en Cracovia, en la Universidad Jaguelónica, y recogía las actas del Primer Simposio de Hispanistas Polacos que tuvo lugar en Cracovia y Mogilany entre el 15 y 17 de diciembre de 1985. Sus redactores, Teresa Eminowicz, Piotr Sawicki y Jerzy Sławomirski, inauguraban así nuestra revista, con un tomo en el que colaboraron algunas de las que ahora son verdaderas personalidades del hispanismo polaco.

El esfuerzo no cesó y, en 1992, también en Wrocław, apareció el segundo tomo de Estudios Hispánicos —editado por Piotr Sawicki y Jerzy Sławomirski-, que en esta ocasión recogía las actas del Segundo Simposio de Hispanistas Polacos celebrado en Wrocław y en Karpacz entre el 24 y el 27 de septiembre de 1990. Desde entonces, la revista se publica en Wrocław como una de las series editoriales bajo el nombre común de Acta Universitatis Wratislaviensis.

En el presente volumen tomamos el testigo del número anterior, que parcialmente recogía los estudios presentados en el simposio internacional "Destierro y destiempo: exilios hispanos y polacos", organizado el pasado año 2017 por el Departamento de Filología Románica de la Universidad de Wrocław y la Escuela Superior de Filología de Wrocław. Completamos de este modo el número vigesimoquinto con los primeros cinco estudios que aquí presentamos y que versan sobre la experiencia del exilio: en primer lugar, el trabajo de Elżbieta Bender hace un análisis de La raíz rota, de Arturo Barea, centrándose en el concepto de destiempo y en las similitudes biográficas del protagonista con su autor. Małgorzata Gaszyńska-Magiera explora Soldados de Salamina de Javier Cercas en el contexto polaco, y lo hace bajo el punto de vista del campo de estudios sobre la memoria. Agnieszka Kłosińska-Nachin realiza un estudio comparativo de la figura del exiliado frente a la Transición española y polaca sobre la base de Crematorio, de Rafael Chirbes, y Niskie Łąki de Piotr Siemion. A continuación encontramos el artículo de Ewa Śmiłek sobre el exilio interior en el que nos presenta una aproximación a la poesía de Luis Álvarez Piñer. Por último, Justyna Ziarkowska lleva a cabo un análisis de la traducción al español de Mi siglo. Confesiones de un intelectual europeo, de Aleksander Wat.

En la sección "varia" hemos incluido textos fuera del ámbito del exilio: la aportación de Adalberto Mejía aborda los temas de espacio y memoria 
en la obra de Sergio Pitol. Edwin Murillo explora la poesía de Manuel Gutiérrez Nájera en el marco del existencialismo. Natalia Szejko y Bartosz Dondelewski analizan la situación sociolingüística de los hablantes de lengua gallega en la década de los 50, basándose en la novela A Esmorga de E. Blanco Amor. Por último, Justyna Tomczak-Boczko hace una aproximación al estereotipo lingüístico del macho en el español de México. Cerramos nuestro tomo con la sección de reseñas y notas de lectura que nos pone al corriente de las novedades editoriales del hispanismo polaco.

Solo nos queda mostrar nuestro agradecimiento tanto al consejo asesor que ha colaborado en este número como a los autores $\mathrm{y}$, cómo no, desear una feliz lectura.

Trinidad Marin Villora y Aleksander Trojanowski 